\title{
CFD Simulations of a Finned Projectile with Microflaps for Flow Control
}

\author{
Jubaraj Sahu \\ U.S. Army Research Laboratory, Aberdeen Proving Ground, MD 21005, USA \\ Correspondence should be addressed to Jubaraj Sahu; jubaraj.sahu.civ@mail.mil
}

Received 9 September 2016; Revised 10 November 2016; Accepted 27 November 2016; Published 19 January 2017

Academic Editor: Antonio Ficarella

Copyright (C) 2017 Jubaraj Sahu. This is an open access article distributed under the Creative Commons Attribution License, which permits unrestricted use, distribution, and reproduction in any medium, provided the original work is properly cited.

This research describes a computational study undertaken to determine the effect of a flow control mechanism and its associated aerodynamics for a finned projectile. The flow control system consists of small microflaps located between the rear fins of the projectile. These small microflaps alter the flow field in the aft finned region of the projectile, create asymmetric pressure distributions, and thus produce aerodynamic control forces and moments. A number of different geometric parameters, microflap locations, and the number of microflaps were varied in an attempt to maximize the control authority generated by the flaps. Steadystate Navier-Stokes computations were performed to obtain the control aerodynamic forces and moments associated with the microflaps. These results were used to optimize the control authority at a supersonic speed, $M=2.5$. Computed results showed not only the microflaps to be effective at this speed, but also configurations with 6 and 8 microflaps were found to generate $25 \%-50 \%$ more control force than a baseline 4-flap configuration. These results led to a new optimized 8-flap configuration that was further investigated for a range of Mach numbers from $M=0.8$ to 5.0 and was found to be a viable configuration effective in providing control at all of these speeds.

\section{Introduction}

The prediction of aerodynamic coefficients for projectile configurations is essential in assessing the performance of new designs. Accurate determination of aerodynamics and flight dynamics is thus critical to the low-cost development of new advanced munitions. Various techniques such as the semiempirical $[1,2]$, wind tunnel $[3,4]$, free-flight [5-8], and computational fluid dynamics (CFD) [9-11] are used routinely for aerodynamic characterization of projectiles without any flow control. The flow fields associated with munitions can be complex at high angles of attack and even at low angles of attack for complex configurations. Body and wing vortices $[12,13]$ can dominate the flow field and interact with one another resulting in a very complex flow field even for simple geometries. With active or passive flow control, the flow fields are generally more complex which in turn makes determination of aerodynamics more challenging and difficult. This is true even for simple base flow control $[14,15]$ used for reduction in base drag and especially true for forebody flow control of asymmetric vortices at high angles of attack [16$18]$.

Active flow control $[19,20]$ involves flow actuators; some examples include fluidic [21, 22], synthetic jet [23, 24], and plasma jet $[25,26]$ actuation. Passive flow control, on the other hand, usually involves geometrical modifications, such as vortex generators [27] on a wing, or strakes [28-30] on a body, or other protuberances $[31,32]$ that are used for flow control applications. For projectile and missile applications, both types of active and passive flow control mechanisms are used to provide aerodynamic control. For a guided munition, aerodynamic control provides the required control force and moment that are then used to maneuver or alter its trajectory as needed. The flow fields associated with these control mechanisms for munitions are complex, involving three-dimensional (3D) shock-boundary layer interactions, jet interaction with the free-stream flow, and highly viscousdominated separated flow regions.

Traditionally, fins, canards, and other control surfaces are often used to provide the required passive control for 
maneuvering projectiles and missiles. A major concern, especially when adding moveable aerodynamic surfaces (e.g., canards) $[33,34]$, upstream of the body or stabilizing fins, is flow interaction. The motion of upstream control surfaces at various aerodynamic angles of attack and Mach numbers greatly influences the pressure distribution on downstream surfaces. Even for unguided flights, these flow interactions exist and must therefore be accurately taken into account in the design analysis for both uncontrolled and controlled flights. Canard control is a preferred way to provide control force and moment required for maneuvering munitions and is effective at both low (subsonic) and high (supersonic) speeds. However, adverse flow interactions downstream can occur on the afterbody at certain flow conditions (speeds and angles of attack) and again must be taken into account in the aerodynamic analysis.

Traditionally, supersonic jets are used for active flow control for high speed projectile and missile applications. Activation of a jet generates a control forces and thus provides the control authority needed to maneuver the flight vehicle. The resulting flow field is highly three-dimensional, unsteady, and very complex with shock structures and separated flow regions even at small angles of attack. This is especially true at high angles of attack where the flow field is complex even without jet interaction. Slender bodies at high angle of attack exhibit complicated flow structures such as asymmetric vortex shedding which induce nonlinear side forces and side moments [12]. One must take into account the jet interaction effects to be able to predict the overall aerodynamic forces and moments acting on the projectile at low to high angles of attack. Accurate numerical modeling of the unsteady aerodynamics can be challenging and generally requires the use of advanced time-accurate CFD solution techniques. Examples of experimental and numerical studies of lateral jet interaction on a finned projectile include both steady-state jets and transient pulse jets [11, 35-38]. Recently, time-accurate CFD was used in case of a pulse jet [39].

Other researchers have looked at other means to provide aerodynamic control with control devices located either in the nose area (nose control) [40-42] or in the afterbody region (rear control) [43]. The nose of the body is often deflected or bent $[40,41]$ creating flow asymmetry resulting in aerodynamic control force and moment. Other nontraditional means include optically generated air channels [44] and electromagnetic aerodynamic control [45].

Recently, many new weapon control mechanisms such as plasma jets $[47,48]$, deployable pins $[49,50]$, microflaps $[46,51-53]$, and microjets $[24,54-56]$ have been investigated for their feasibility for providing sufficient control forces and moments for projectile control and other applications. These control mechanisms result in highly complex unsteady flow interactions and must be taken into account properly for accurate prediction of aerodynamics. Clearly, some of these new flow control mechanisms are unconventional and more research is needed to fully understand the flow interaction effects and accurately predict the aerodynamics and flight dynamics and hence overall guided flight performance. From a computational standpoint, accurate modeling of the critical flow interaction phenomena during guided flight control is a major challenge in terms of both numerical solution techniques and computing resources required. Fortunately, improved computer technology and state-of-the-art numerical procedures now enable solutions to complex 3D problems associated with projectile and missile aerodynamics both without and with flow control. CFD thus offers a viable approach for obtaining aerodynamics of projectiles with traditional or new flow control mechanisms.

Recently, a number of studies, both experimental and computational, have been conducted in exploring these flow control mechanisms for projectile control. Massey et al. [49] studied the effect of pin-based actuators for control of a projectile at supersonic speeds. Later, the projectile was flight tested [50] to determine the feasibility of these actuators for projectile control. These studies have indicated some potential of the pin-based actuators for projectile control at supersonic speeds. Another control mechanism that is similar to the pin-based actuator consists of a set of small microflaps [46, 51-53]. This new flow control mechanism has recently been investigated for feasibility of providing adequate aerodynamic control and is also used in the present research. In this case, the flow control is achieved by locating the small microflaps between rear fins of the finned projectile. The rear location of the microflaps offers an advantage in that one does not need to worry about any adverse flow interaction effects commonly associated with canards and jets because of their upstream location. At supersonic speeds these microflaps alter the flow field in the finned region of the projectile due to shock wave interactions between the body, fins, and microflaps. These flow interactions result in asymmetric pressure distribution over the rear finned section and thus produce control forces and moments. Cler et al. [51] and Dykes et al. [52] used a flat-plate fin interaction design of experiments model to examine the level of control authority at Mach 1.7 and obtained an optimized layout with 4 microflaps. Sahu and Heavey [46] computationally studied the effect of microflaps on the aerodynamics of a finned projectile using the same set of 4 flaps. Computed results indicated that the microflaps were effective at supersonic speeds and not effective at transonic speeds. The aerodynamic characterization work reported by Scheuermann et al. [53] contained both computational and flight test results. Resulting aerodynamic models were found to be in generally good agreement and continued to show promise for microflaps as a viable control mechanism at supersonic speeds $(2<$ $M<3$ ). These previous studies using microflaps were largely based on the 4-flap configurations; the effect of the number of flaps was not investigated. Also, earlier optimization that led to the 4-flap configuration did not include the actual finned projectile geometry and was done on a flat plate [52]. Some preliminary results were reported by Sahu [57] with optimization performed on an actual finned configuration.

In the present study, the focus is again on generation of maximum control authority on a real finned projectile configuration. This detailed study now includes a number of different geometric parameters, microflap locations, and numbers of microflaps that are used to maximize the control authority generated by the flaps. In addition, the present study investigates the flow control performance of the optimized 
configuration at various speeds from subsonic to supersonic ( $M=0.8$ to 5.0$)$. Computed results obtained are compared with that of the baseline configuration with 4 microflaps. In all cases, steady-state CFD is used to investigate the level of control forces and moments due to the interaction of body, fins, and microflaps flow fields. Computed control forces and moments generated by the microflaps are also currently being used in a six-degree-of-freedom (6DOF) flight dynamic analysis to demonstrate cross-range control of the finned projectile.

\section{Computational Methodology}

The CFD capability used here solves the full three-dimensional (3D) Navier-Stokes equations in a time-dependent manner for simulations of projectile flow fields. A commercially available Navier-Stokes flow solver, CFD++ [58-60], is used in the present work. The basic numerical framework in the solver contains unified-grid, unified-physics, and unifiedcomputing features. Details of the basic numerical framework can be found in $[58,59]$. Here, only a brief synopsis of this framework and methodology is given. A finite volume method is used to solve the 3D time-dependent ReynoldsAveraged Navier-Stokes (RANS) equations

$$
\frac{\partial}{\partial t} \int_{V} \mathbf{W} d V+\oint[\mathbf{F}-\mathbf{G}] \cdot d A=\int_{V} \mathbf{H} d V
$$

Here, $\mathbf{W}$ is the vector of conservative variables, $\mathbf{F}$ and $\mathbf{G}$ are the inviscid and viscous flux vectors, respectively, $\mathbf{H}$ is the vector of source terms, $V$ is the cell volume, and $A$ is the surface area of the cell face.

Implicit local time-stepping and relaxation techniques were used to achieve faster convergence. Use of an implicit scheme circumvents the stringent stability limits encountered by their explicit counterparts, and successive relaxation allows update of cells as information becomes available and thus aids convergence. CFD++ uses an algebraic multigrid approach as the means to efficiently solve the linear algebra problem that results in applying an implicit scheme to both steady-state and unsteady modes of operation. In the present work, only steady-state solutions have been obtained.

The governing RANS equations (1) were marched in time using a point-implicit time integration scheme with local time-stepping, defined by the Courant-Friedrichs-Lewy (CFL) number until solutions converged. Initially, the flow solution started with free-stream conditions in the entire domain. For supersonic flow cases, CFL number was ramped from 1 to 40 over the first 100 iterations and then remained unchanged until converged solutions were obtained. At transonic and subsonic speeds, the maximum CFD number was set at 100. Five orders of magnitude reduction in the residuals of the RANS equations was achieved within 10001500 iterations and within 3000-4000 iterations at supersonic and subsonic speeds, respectively. Additionally, the total aerodynamic forces and moments were monitored and found to converge a lot faster, usually within 500 iterations.
Second-order discretization was used for the flow variables and turbulent viscosity equations. The spatial discretization was a second-order, upwind scheme and used a HartenLax-van Leer-Contact (HLLC) Riemann solver in conjunction with a multidimensional Total-Variation-Diminishing (TVD) flux limiter. Supersonic flow cases required the use of a first-order discretization over the first 200 iterations. A blending function was used to transition from first- to second-order discretization over the next 100 iterations.

For computation of turbulent flows that are of interest here, a realizable $k-\varepsilon$ model [61] provided the turbulence closure. This two-equation turbulence model solves two transport equations, one for the turbulent kinetic energy $(k)$ and the other for the turbulent dissipation rate $(\varepsilon)$. These two turbulence variables are then used to obtain the turbulent eddy viscosity using Boussinesq assumption. This turbulence model has been successfully and routinely used in a number of projectile and other aerodynamics applications. The turbulence equations were fully solved all the way to the wall of the projectile and required high resolution meshes near the projectile surface wall (nondimensional wall distance, $y+\leq$ 1.0). Free-stream values of $k$ and $\varepsilon$ were obtained using a freestream turbulence intensity of $2 \%$ and a turbulent-to-laminar viscosity ratio of 50 .

\section{Model Geometries and Computational Grids}

The projectile modeled in this study is the Basic Finner, a cone-cylinder-finned configuration [3]. A schematic diagram of the Basic Finner shape is shown in Figure 1. The length of the projectile is $10 \mathrm{cal}$. and the diameter is $30 \mathrm{~mm}$. The conical nose is $2.84 \mathrm{cal}$. long and is followed by a $7.16 \mathrm{cal}$. cylindrical section. Four rectangular fins are located on the back end of the projectile. Each fin is $1 \mathrm{cal}$. long, has a sharp leading edge, and is $0.08 \mathrm{cal}$. thick at the trailing edge. The center of gravity is located $5.5 \mathrm{cal}$. from the nose of the finned projectile.

Figure 2 shows the 3D computational models of the finned projectile both without and with microflaps. Figure 2(b) shows a typical set of 6 microflaps, the control mechanisms, in this case located in 3 rows between 2 of the 4 rear fins. These microflaps, located as shown in Figure 2, are intended to create asymmetric pressure distributions and flow fields in the aft finned section of the projectile and provide control forces and moments needed for projectile control maneuver. A number of geometric parameters as well as the number of microflaps were varied. Geometric parameters included the axial and the circumferential distances or spacings between the microflaps. The circumferential distances between the microflaps were chosen by defining the angle between them. The flap thickness is about $0.512 \mathrm{~mm}$ and its height is $4.54 \mathrm{~mm}$. Table 1 below shows the geometric parameters for the 6- and 8-flap configurations. The first axial spacing is the distance between the leading edge of the fins and the first row of microflaps. The other axial spacings represent the axial distances between the front faces of the microflaps.

Unstructured meshes were generated for all configurations without and with flaps using MIME, an unstructured mesh generator developed by Metacomp Technologies. 


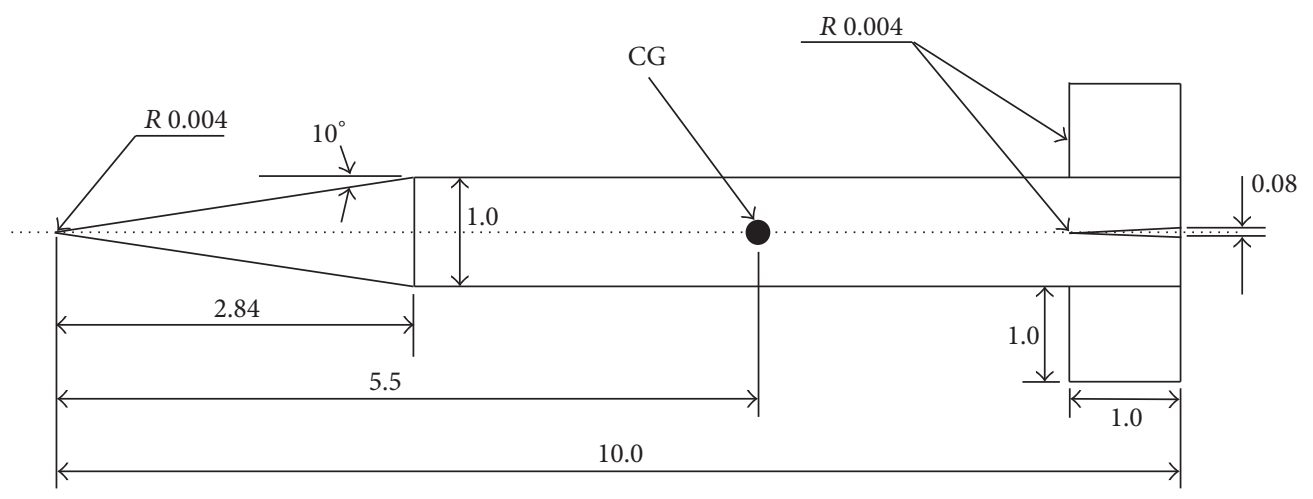

Figure 1: Schematic of the basic finned configuration (in calibers; 1 cal. $=0.03 \mathrm{~m}$ ).

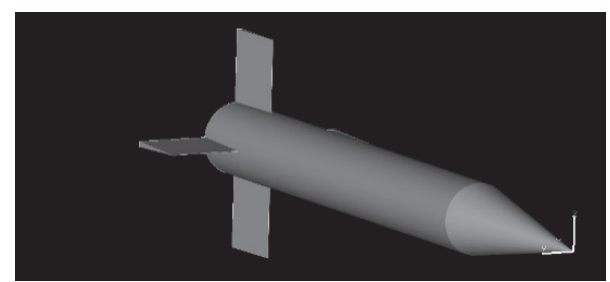

(a)

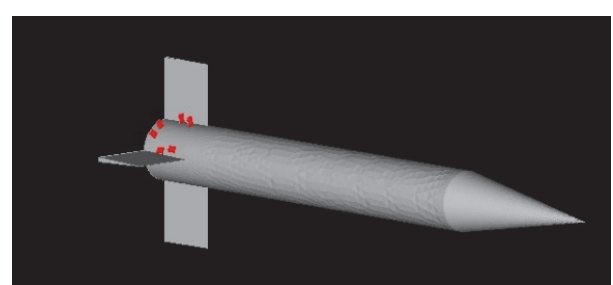

(b)

FIGURE 2: Finned body geometry (a) without and (b) with microflap control mechanisms between 2 rear fins.

TABLE 1: Geometric parameters used for various microflap configurations.

\begin{tabular}{lcc}
\hline Cases & Axial spacing $(\mathrm{m})$ & $\begin{array}{c}\text { Circumferential } \\
\text { spacing in } \\
\text { angles }\left(^{\circ}\right)\end{array}$ \\
\hline Case 1: 6 flaps & $0.0079,0.0079,0.0079$ & $60,70,20$ \\
Case 2: 6 flaps & $0.0079,0.0079,0.0079$ & $60,40,20$ \\
Case 3: 6 flaps & $0.0079,0.0079,0.0079$ & $20,40,60$ \\
Case 1: 8 flaps & $0.006,0.006,0.006,0.006$ & $20,35,50,20$ \\
Case 2: 8 flaps & $0.006,0.006,0.006,0.006$ & $65,50,35,20$ \\
Case 3: 8 flaps & $0.006,0.006,0.006,0.006$ & $20,35,50,65$ \\
\hline
\end{tabular}

Figure 3 shows the computational mesh for the projectile configuration without microflaps. The mesh consists of 3.4 million cells and 3.6 million nodes. Three different types of cells-tetrahedrons, triangular prisms, and pyramids-were used in the mesh. Grid points as shown in Figure 3(a) were clustered in the boundary layer region near the projectile body. The boundary spacing was selected to achieve a $y+$ value of 1.0 or less. Other regions of grid clustering included the fins and the wake regions. An expanded view of the mesh for the afterbody fin region is shown in Figure 3(b). It shows the surface mesh and the clustering used at the leading and trailing edges of the fins.

The same unstructured technique was used to generate the meshes for the projectile configurations with the microflaps. It should be noted that a new mesh was generated every time with any change in the number of microflaps or location or height of microflaps. As pointed out earlier, the microflaps were located between 2 of the 4 rear fins. Figure 4 shows the surface meshes in the afterbody fin region containing the microflaps. Figure 4(a) shows a typical set of meshes for the three 6-flap configurations considered, while Figure 4(b) shows the same for the three 8-flap configurations. The flaps are located in 3 or 4 rows symmetrically about the $z$-axis; the meshes shown in Figure 4 correspond to the $x y$ plane ( $z$-axis $\perp$ to the board). In general for the projectile configurations with microflaps, most of the grid points were clustered in the boundary layer, fins, microflaps, and wake regions. The overall unstructured meshes consisted of about 4 to 5 million cells and 4.5 to 5.5 million nodes. The increased grid density for the finned body with microflaps can also be seen on the cylinder surface between the fins. The boundary spacing was selected to achieve a $y+$ value of 1.0, and integration of governing equations was carried out all the way to the body wall. For some cases, a finer set of meshes ranging from 13 to 15 million cells were also created and used.

\section{Results}

Numerical simulations for the projectile both with and without flow control have been carried out at the US Air Force Defense Supercomputing Resource Center with a Cray XE-6 system using 64 processors. These computations have been performed using the advanced scalable unstructured flow solver CFD++ with a time-dependent Navier-Stokes computational technique as described earlier. In all cases, full 3D computations using atmospheric sea level flight conditions were performed and no symmetry was used. 


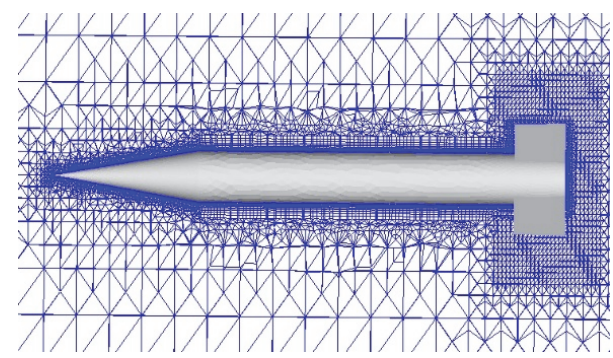

(a)

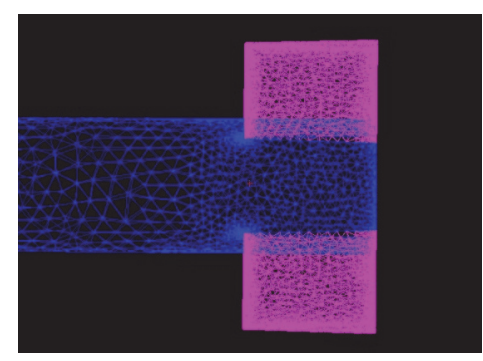

(b)

FIGURE 3: Computational grid without microflaps, expanded near (a) the projectile and (b) afterbody finned region.
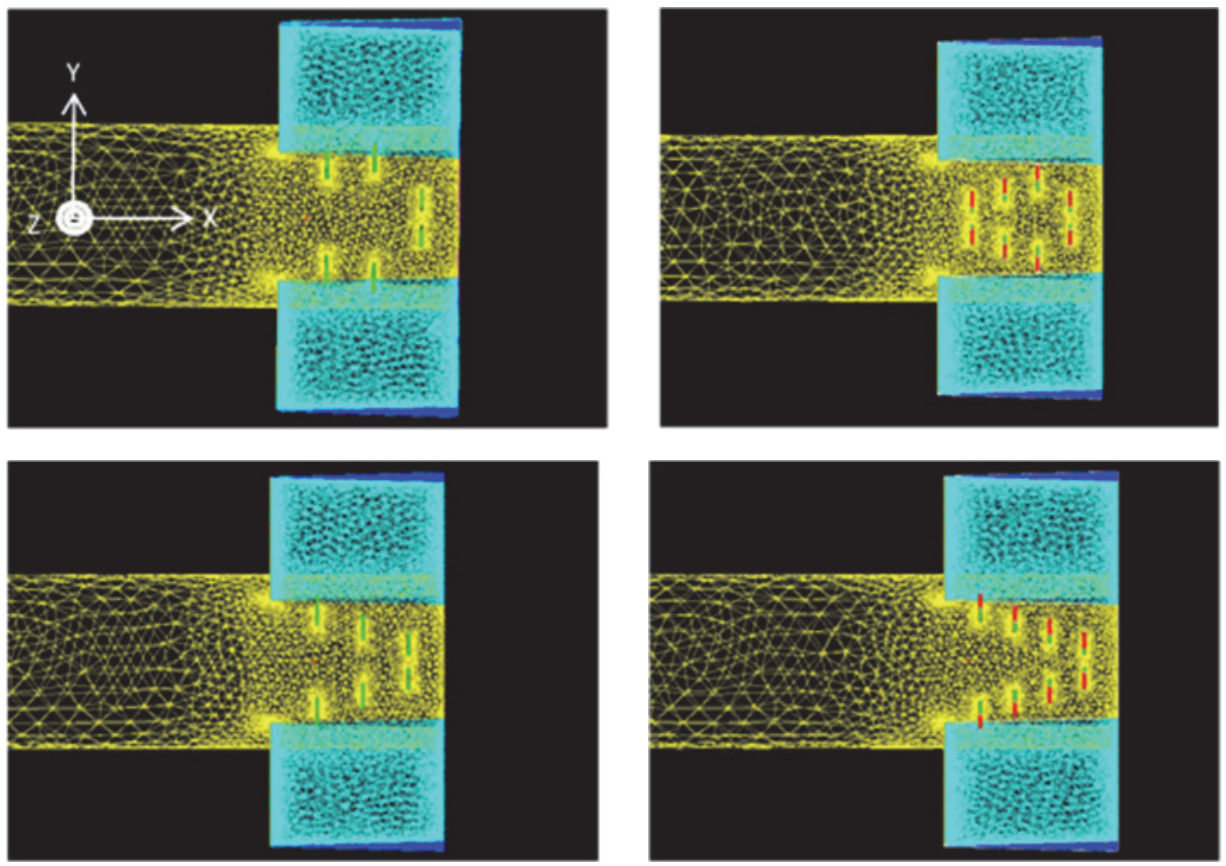

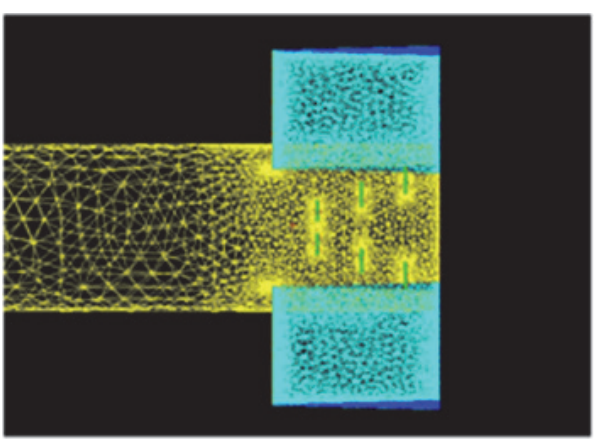

(a)

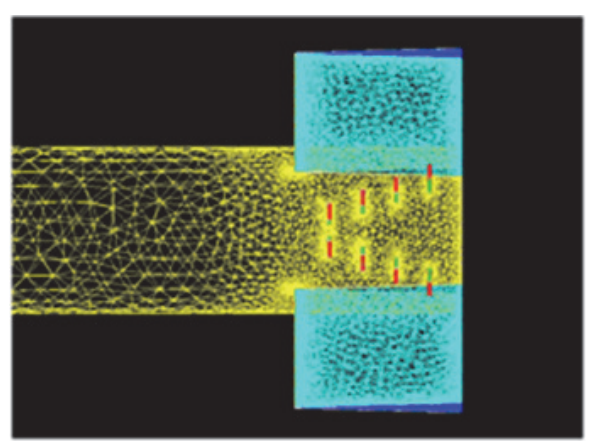

(b)

FIgURE 4: Computational grids with microflaps: (a) 6- and (b) 8-flap cases.

Steady-state computations have been performed for the finned projectile both without and with microflaps at $M=2.5$ and at angle of attack $\alpha=0^{\circ}$. Solutions were obtained at $\alpha=2^{\circ}$ for the case with no flaps. Although not shown here, computed slopes of normal force and pitching moment coefficients, $C_{\mathrm{N} \alpha}$ and $C_{\mathrm{m} \alpha}$, obtained for the finned projectile without microflaps were checked and found to be in very good agreement with the test data $[3,6]$. For the body without microflaps, computed solutions with finer meshes (13 to 15 million cells) produced essentially similar aerodynamic forces and moments (within one or two percent) compared to solutions with less fine meshes (4 to 5 million cells). 
TABLE 2: Delta forces and moments due to microflaps, $M=2.5, \alpha=0^{\circ}$.

\begin{tabular}{lccc}
\hline Cases & Delta normal force $\delta F_{z}(\mathrm{~N})$ & Delta pitching moment $\delta M_{y}(\mathrm{~N}-\mathrm{m})$ & Delta axial force $(\mathrm{N})$ \\
\hline 4 flaps, [46] & -40.0 & 4.20 & 17.0 \\
Case 1: 6 flaps & -47.5 & 5.87 & 19.9 \\
Case 2: 6 flaps & -50.2 & 6.23 & 20.0 \\
Case 3: 6 flaps & -50.8 & 6.34 & 21.2 \\
Case 1: 8 flaps & -51.4 & 6.25 & 20.2 \\
Case 2: 8 flaps & -52.5 & 6.34 & 21.6 \\
Case 3: 8 flaps & -55.5 & 6.80 & 23.1 \\
1-flap case & -11.0 & 1.50 & 6.0 \\
\hline
\end{tabular}

Grid independency was also tested with less fine and finer meshes for the body with microflaps and again, differences in the results were found to be very small. Therefore, less fine meshes were used for the optimization study described next at $M=2.5$ and $\alpha=0^{\circ}$. Once an optimized configuration was obtained, more fine mesh was used on it to determine the control force and moment across Mach numbers from subsonic to supersonic speeds and a range of angles of attack. All solutions were obtained with RANS technique and a two-equation realizable $k-\varepsilon$ model. For supersonic flows, this approach has been applied successfully in a number of projectile applications and found to be adequate. The separated flow regions behind the microflaps are rather small and are expected to be predicted correctly with the $k-\varepsilon$ model for supersonic flows that are of utmost interest here. Higher order RANS/LES or LES models are not really needed for optimization study. Also, steady approach again is more efficient for the optimization study.

4.1. Optimization of Control Authority. For cases with flaps, computations were performed to quickly provide the extent of control forces that could be generated using the microflaps. The microflaps were pointing up in the $z$-direction in all these cases with the fins in the $x$-orientation and were located symmetrically about the $z$-axis. This way, no side forces were created and the control force and moment of interest were the normal force, $F_{z}$, and the associated pitching moment, $M_{y}$, respectively.

Figure 5 shows the computed surface pressure contours for the finned body with the microflaps at $M=2.5$ and $\alpha$ $=0^{\circ}$ for the different flap cases. Computed surface contours for the three 6-flap cases are shown in Figure 5(a), while Figure 5(b) shows the results for the three 8-flap cases. In Figure 5, the flow field between the 2 fins is quite complicated when the microflaps are present. There are a lot of body, fin, and microflaps flow interactions, resulting in very complex flow fields containing multiple shocks and regions of high surface pressures. High surface pressures are shown in red and yellow, and blue represents lower pressures. As expected, the pressures in front of the flaps are high, and lower-pressure regions are observed behind the flaps, especially the last row of flaps. For the 6-flap cases, the top 2 configurations seem to show similar flow structures. The third 6-flap case (bottom picture in Figure 5(a)) shows much stronger shock-shock interactions, resulting in larger region of higher pressures on the fins. The same is true of the 8-flap cases, as shown in the top and bottom plots of Figure 5(b). The first 3 rows of flaps are the same between these 2 plots; the only difference is in the circumferential location of the flaps in the last row. For both the 6- and 8-flap cases, the pictures on the bottom of Figure 5 are perhaps the best cases showing the larger regions of higher pressures than other cases.

As shown in Figure 5, the strong shock interactions due to the presence of the flaps result in regions of higher pressures between the fins on the lee side (top view). On the other hand, the computed surface pressures on the afterbody between the other fins are similar to the no-flap case and show only the interaction of 2 weak shocks, and the flow field is rather a simple one (Figure 6). The surface pressures are much lower on the wind side than the lee side where the microflaps were located. The difference in the surface pressures between the lee side and the wind side results in a negative normal force, $F_{z}$. Also, for the finned projectile without the microflaps, the normal force, as expected, is zero and so is the pitching moment at $\alpha=0^{\circ}$.

The actual change (delta) in the aerodynamic forces and moments between the Finner with microflaps and the Finner without microflaps was obtained from the computed solutions for all configurations at $M=2.5$ and $\alpha=0^{\circ}$ and is shown in Table 2. The delta normal force and the delta pitching moment are of primary interest here. For comparison purposes, the computed result for a 4-flap configuration from Sahu and Heavey [46] is included in the first row of the table. Also included in the last row of the table is the result obtained for a 1-flap configuration (Figure 7). One flap alone produces $11 \mathrm{~N}$ of control force and a pitching moment of $1.5 \mathrm{Nm}$. The flap was not perfectly placed symmetrically in this case and thus the flow field does show some asymmetry. The remaining cases include three 6-flap and three 8-flap configurations. As shown in Table 2, all 6 of these flap configurations produce normal force in the range of 47-56 N compared with $40 \mathrm{~N}$ obtained with a 4-flap configuration. It seems that the larger the number of flaps, the larger the control normal force and pitching moment, especially with the 6-flap configurations. However, the net gain in control force and moment in going from 6 to 8 flaps is smaller than that achieved in going from 4 to 6 flaps. As explained earlier in Figure 5, case 3 from the 6-flap arrangement and case 3 from the 8-flap 

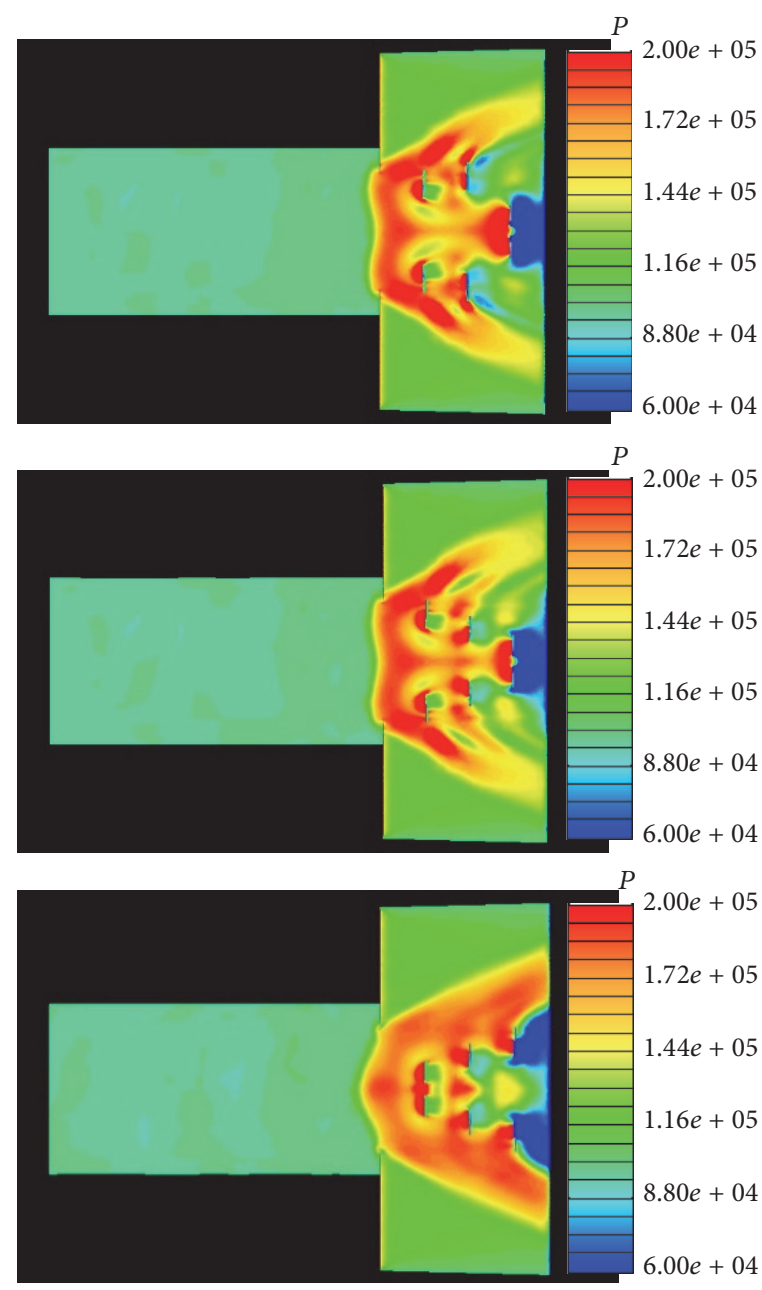

(a)
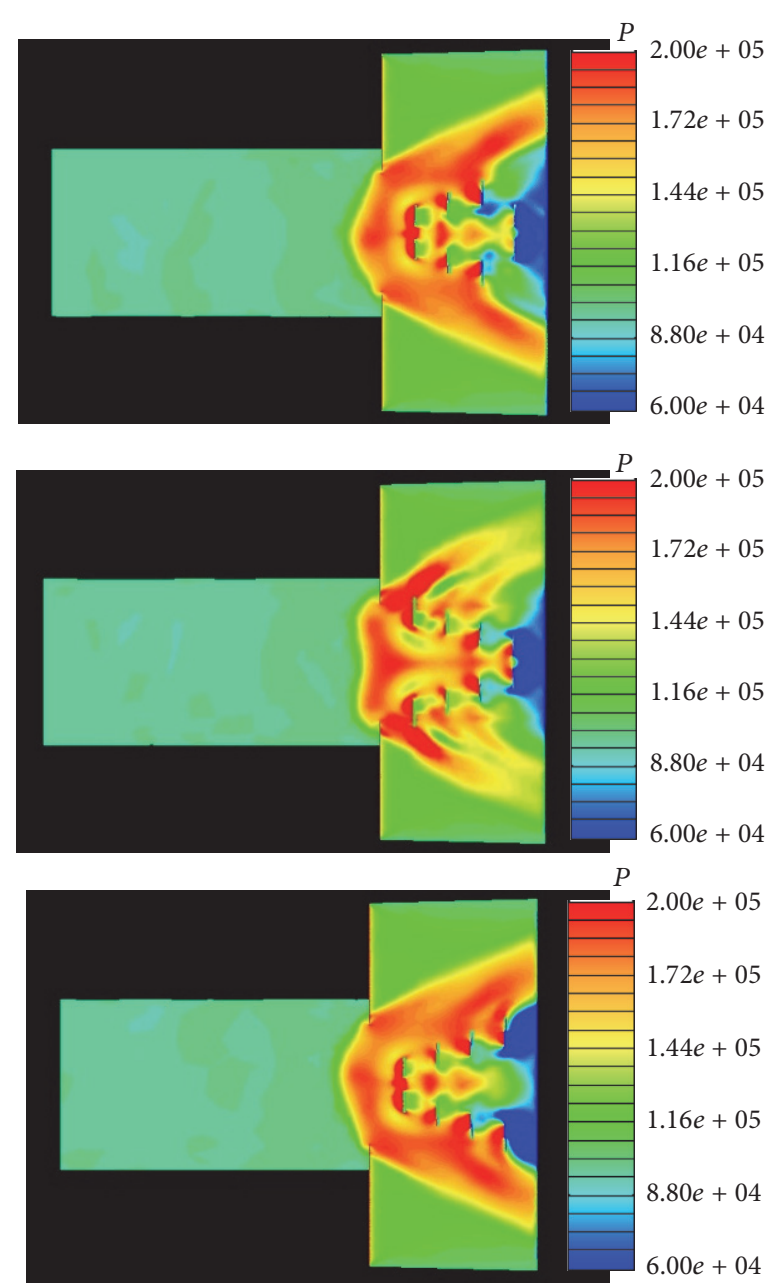

(b)

FIGURE 5: Computed surface pressure contours in the afterbody fin region near the microflaps, $M=2.5, \alpha=0^{\circ}$ : (a) 6-and (b) 8-flap cases.

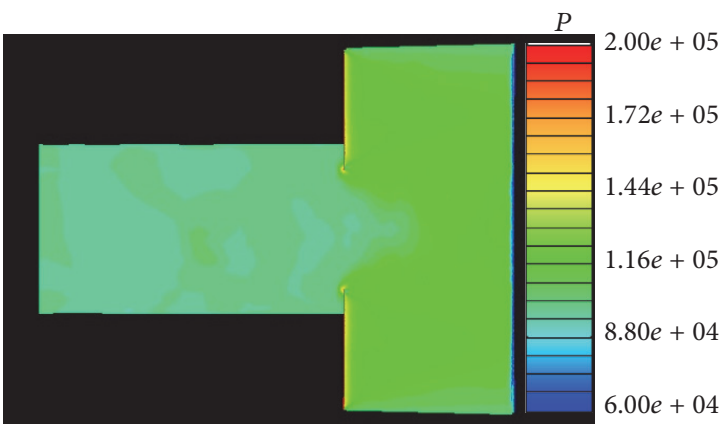

FIGURE 6: Computed surface pressure contours between the fins in the wind side, $M=2.5, \alpha=0^{\circ}$.

arrangement show larger regions of high pressures especially on the fins and are perhaps the best cases that produce the most control force and moment. Since the microflaps were located symmetrically with respect to the $z$-axis, the $F_{y}$ force and the moments, $M_{x}$ and $M_{z}$, are zero and so are the deltas in those force and moments. Note the drag penalty that results from the presence of microflaps. The increase in drag for all 6- and 8-flap configurations is also included in the table and is generally in the same range. One can thus maximize the control normal force and pitching moment to obtain the best configuration possible.

As discussed earlier, case 3 from the 6- and 8-flap configurations (Table 1 and Figure 5) seemed to be the best case for control force and moment. In the results in Figure 5, especially the bottom row pictures, there are large regions of lower pressures shown in blue. If these regions of lower surface pressures could be eliminated or at least reduced, it could possibly lead to overall higher surface pressures in the whole region containing the microflaps and, ultimately, larger control force and moment. One idea to achieve this was to change the axial distances between the different rows of microflaps such that the last row of microflaps sat right at the end of the projectile flush with the base (Figure 8). The actual axial distances are shown in Table 3 as case 4 for both new 6- and 8-flap configurations. Table 3 also includes case 3 for comparison purposes. Compared with case 3 for the 6-and 8 -flap configurations, where the rows of flaps were equally 


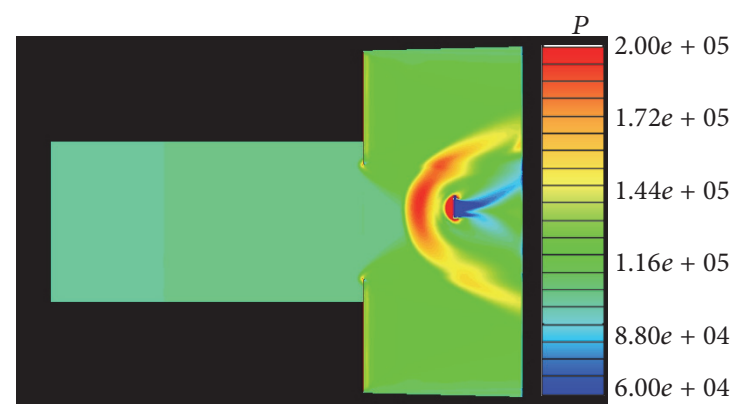

FIGURE 7: Computed surface pressure contours in the afterbody fin region near the microflap for a 1-flap case, $M=2.5, \alpha=0^{\circ}$.

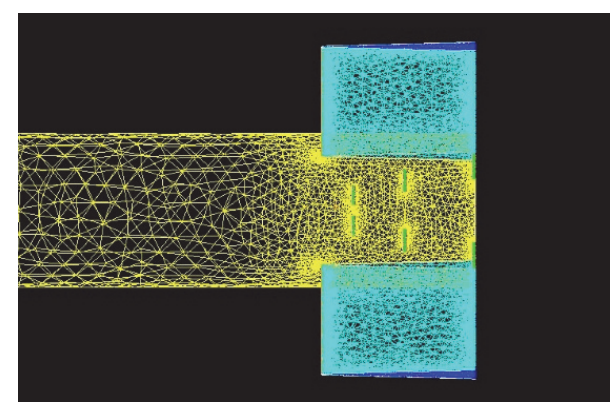

(a)

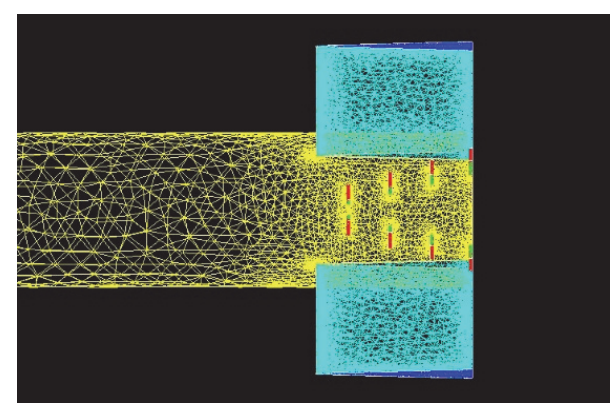

(b)

FIGURE 8: Computational grids for the new microflap cases: (a) 6 and (b) 8 flaps.

TABLE 3: New geometric parameters used for 2-microflap configurations (case 4 ).

\begin{tabular}{lcc}
\hline Case & Axial spacing $(\mathrm{m})$ & $\begin{array}{c}\text { Circumferential } \\
\text { spacing in } \\
\text { angles }\left(^{\circ}\right)\end{array}$ \\
\hline Case 3: 6 flaps & $0.0079,0.0079,0.0079$ & $20,40,60$ \\
Case 4: 6 flaps & $0.006,0.01,0.01349$ & $20,40,60$ \\
Case 3: 8 flaps & $0.006,0.006,0.006,0.006$ & $20,35,50,65$ \\
Case 4: 8 flaps & $0.006,0.008,0.008,0.00749$ & $20,35,50,65$ \\
\hline
\end{tabular}

spaced between the leading edge and the trailing edge of the fins, the first axial spacing between the leading edge of the fins and the first rows of flaps was first set to $0.006 \mathrm{~m}$ and then increased for the remaining rows to push the last row to the trailing edge of the fins or the end of projectile. This was done in an attempt to maximize the surface pressures both ahead of the first row of flaps and eliminate the lowerpressure region behind the last row of flaps seen previously. The circumferential spacings for both of these new cases were kept unchanged from case 3 of both 6-flap configuration and the 8-flap configuration.

Computed surface pressure contours for the 2 new 6and 8-flap configurations are shown in Figures 9(a) and 9(b), respectively. These results, shown as case 4 and case 3 results, are included here for direct comparison with case 4 results. In Figure 9, the lower-pressure regions are shown in blue, with case 3 having largely been eliminated with the new 6- and 8-flap configurations. There is a small region of
TABle 4: Comparison of delta forces and moments, case 3 versus case $4, M=2.5, \alpha=0^{\circ}$.

\begin{tabular}{lccc}
\hline Cases & $\begin{array}{c}\text { Delta normal } \\
\text { force } \delta F_{z}(\mathrm{~N})\end{array}$ & $\begin{array}{c}\text { Delta pitching } \\
\text { moment } \\
\delta M_{y}(\mathrm{~N}-\mathrm{m})\end{array}$ & $\begin{array}{c}\text { Delta axial } \\
\text { force }(\mathrm{N})\end{array}$ \\
\hline Case 3: 6 flaps & -50.8 & 6.34 & 21.2 \\
Case 4: 6 flaps & -55.2 & 6.93 & 21.6 \\
Case 3: 8 flaps & -55.5 & 6.80 & 23.1 \\
Case 4: 8 flaps & -60.6 & 7.56 & 23.7 \\
\hline
\end{tabular}

lower pressures behind the second row of flaps in the 6-flap configuration, but overall the surface pressures downstream are much larger for case 4 . These larger surface pressures clearly lead to larger control force and moment for the new 6and 8-flap configurations (Table 4). As seen in Table 4, case 4 now represents even better candidates for maximum control authority with approximately $5 \mathrm{~N}$ of additional control force achieved compared with case 3 without adding any significant additional drag penalty.

4.2. Effect of Flap Height. A few cases have been run in an attempt to quantify the effect of changing microflap heights, in particular staggering the heights from low in the first row of flaps to high in the last row. Again, both 6-flap configurations and the 8-flap configurations were considered. For each configuration, the heights were changed linearly from $h$ to $2 \mathrm{~h}$ for case 5 and $0.5 \mathrm{~h}$ to $\mathrm{h}$ for case 6 . Here, $\mathrm{h}$ is the original height used in cases 1-4. Computed surface pressure contours 


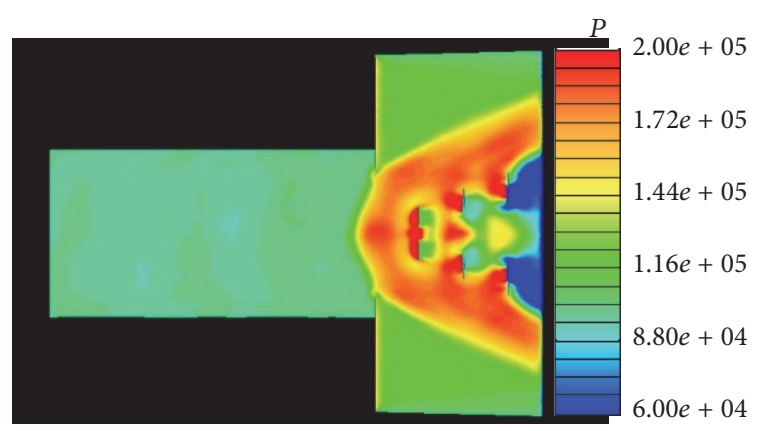

Case 3

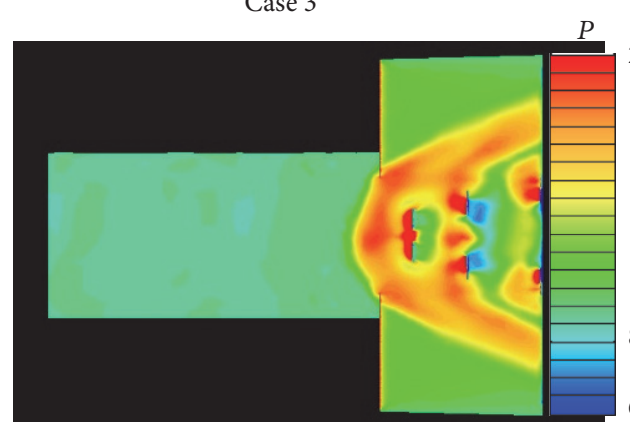

Case 4

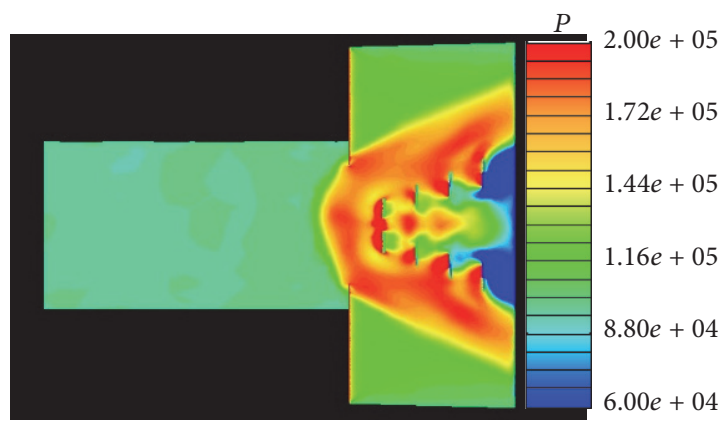

Case 3

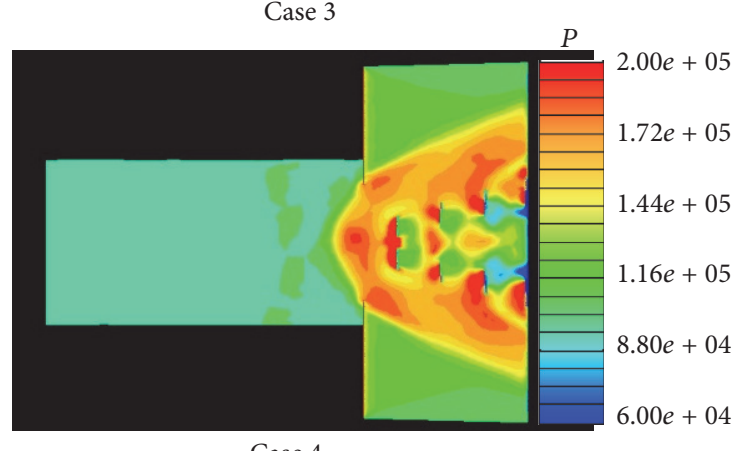

(b)

FiguRE 9: Computed surface pressure contours in the afterbody fin region near the microflaps, case 3 versus case $4, M=2.5, \alpha=0^{\circ}$ : (a) 6 and (b) 8-flap cases.

TABLE 5: Comparison of delta forces and moments, case 5 versus case $6, M=2.5, \alpha=0^{\circ}$.

\begin{tabular}{lccc}
\hline Cases & $\begin{array}{c}\text { Delta normal } \\
\text { force } \delta F_{z}(\mathrm{~N})\end{array}$ & $\begin{array}{c}\text { Delta pitching } \\
\text { moment } \\
\delta M_{y}(\mathrm{~N}-\mathrm{m})\end{array}$ & $\begin{array}{c}\text { Delta axial } \\
\text { force }(\mathrm{N})\end{array}$ \\
\hline Case 5: 6 flaps & -83.0 & 10.84 & 42.4 \\
Case 5: 8 flaps & -97.2 & 12.57 & 46.1 \\
Case 6: 6 flaps & -36.3 & 4.66 & 13.2 \\
Case 6: 8 flaps & -40.9 & 5.21 & 14.6 \\
\hline
\end{tabular}

for the 2 new 6 -flap and 2 new 8 -flap configurations are shown in Figures 10(a) and 10(b), respectively. In case 5, the increase in height for the flaps from $\mathrm{h}$ to $2 \mathrm{~h}$, as expected, created a lot more interactions and increase in surface pressures in the whole region and especially on the fins containing the flaps. On the other hand, in case 6, decreasing the heights from $\mathrm{h}$ in the back row to $0.5 \mathrm{~h}$ in the front basically reduced the interaction region, leading to lot lower surface pressures in this region compared with case 5 .

The resultant control forces and moments are shown in Table 5 for the cases with changing flap heights. Clearly, reducing the heights from the original one in case 6 produces similar or less control force than the baseline case, but the drag penalty is a little less, true for both 6- and 8-flap configurations. The best case seems to be case 5 , where the heights were increased from $\mathrm{h}$ in the first row to $2 \mathrm{~h}$ in the last row of flaps. A very large control force and, correspondingly, a large control moment are obtained for both 6- and 8-flap configurations; however, associated with large control force and moment is also a large, undesirable increase in drag.

4.3. Effect of Angle of Attack. All the results presented here for different angles of attack are again at the same Mach number, $M=2.5$. Again the effect of angle of attack is studied using one of the best candidate configurations, case 4 with 8 flaps. Computed results have been obtained for this 8-flap configuration at various angles of attack from $-16^{\circ}$ to $16^{\circ}$. The resultant delta control forces and moments are shown in Table 6. These results seem to indicate that control force and moment are generated across the range of angle of attack considered here. Also, the variation with angle of attack is not as significant for positive angles of attack; however, for negative angles of attack, the deltas in control forces and moment get larger with increase in angles of attack.

4.4. Effect of Mach Number. All the results presented so far have been at one Mach number, $M=2.5$. Of critical importance is the flow control performance of the microflaps at other speeds (transonic and subsonic) as well. Here the effect of Mach number is studied using the optimized 8-flap configuration (case 4). Computed results have been obtained for this 8-flap configuration at various speeds from $M=0.8$ to 5.0 .

Computed surface pressures in the afterbody region near the microflaps are shown in Figure 11 at different Mach numbers and $\alpha=0^{\circ}$. As shown, the higher the Mach number, the larger the extent of flow interactions. At supersonic 

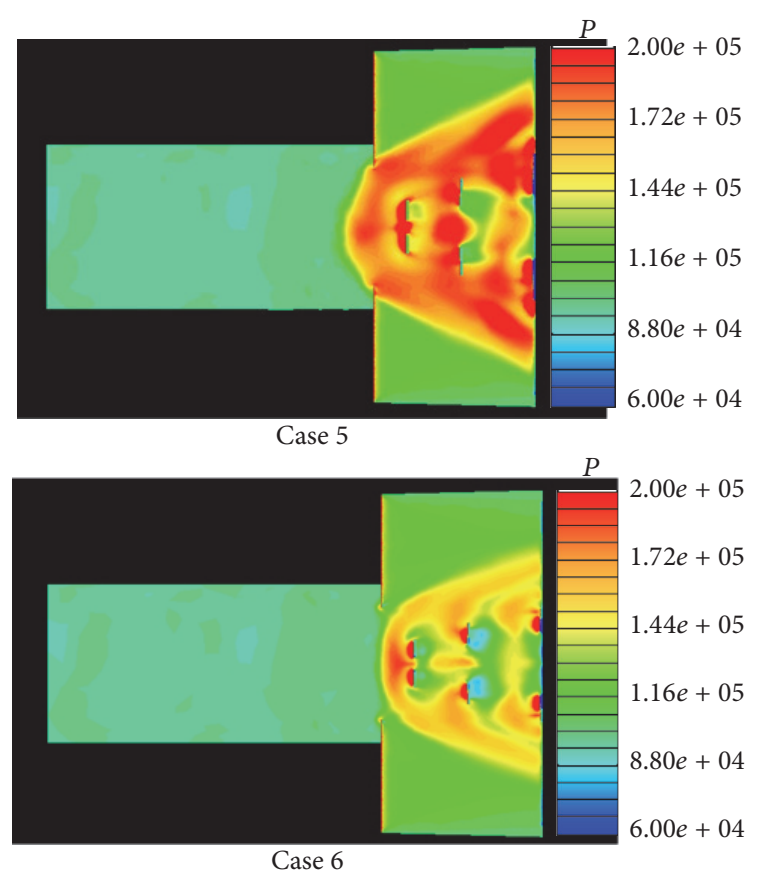

(a)

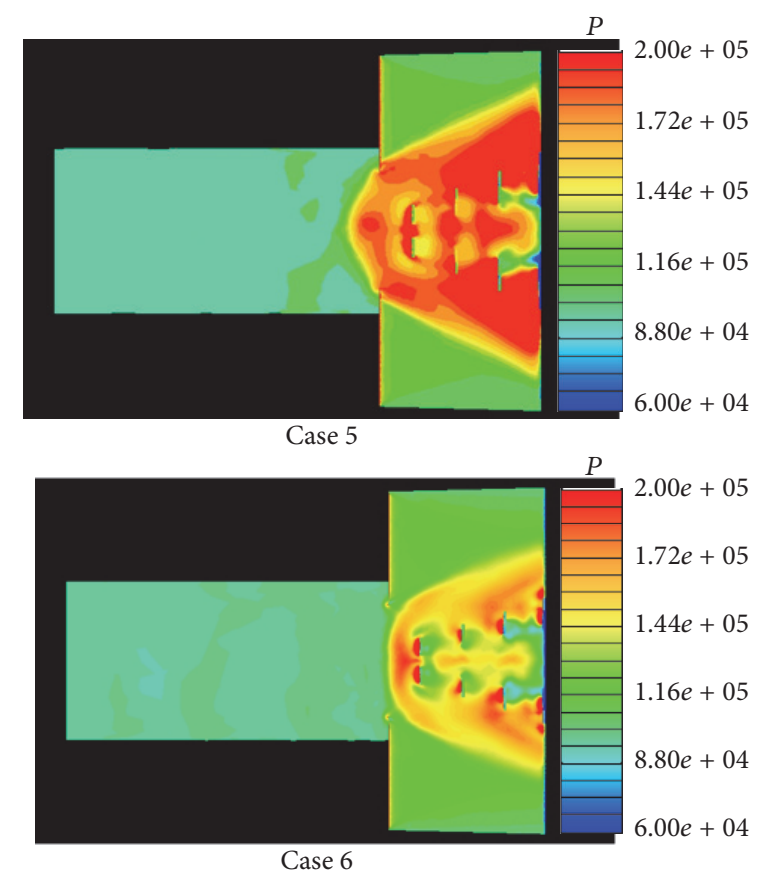

(b)

FIGURE 10: Computed surface pressure contours in the afterbody fin region near the microflaps, flap height variation, $M=2.5, \alpha=0^{\circ}:(\mathrm{a}) 6$ and (b) 8-flap cases.

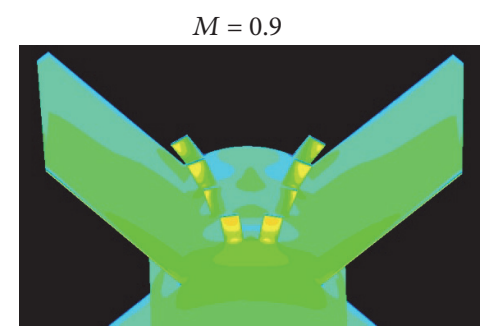

$M=2.0$

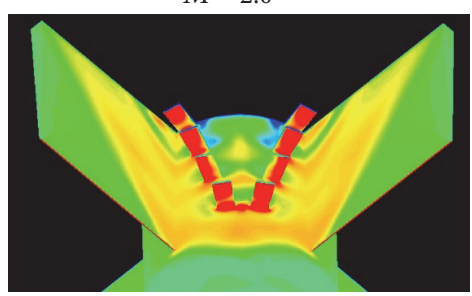

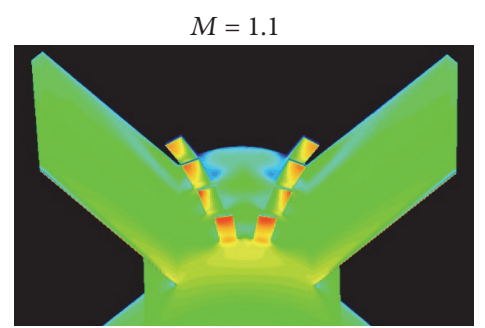

$M=2.5$

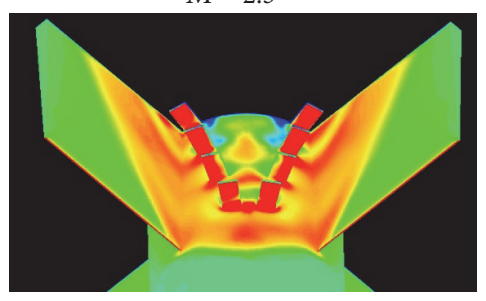

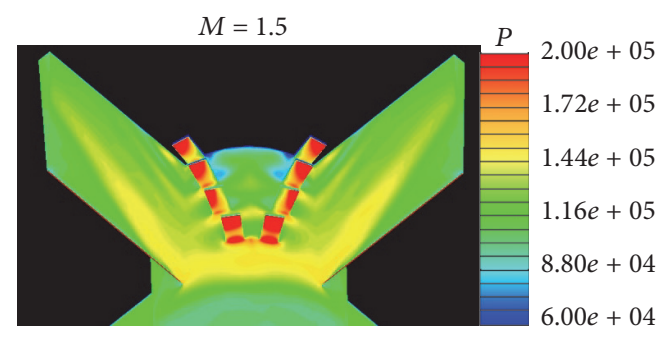

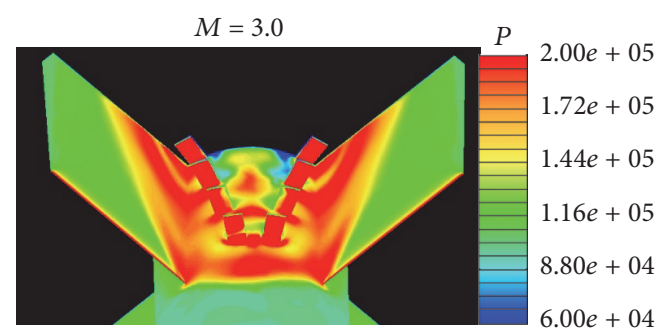

FIGURE 11: Computed surface pressure contours in the afterbody fin region near the microflaps for the 8-flap optimized configuration at various Mach numbers, $\alpha=0^{\circ}$.

speeds, one can see shock interactions and a complex shock structure in the afterbody region containing the flaps. With increasing speed in the supersonic regime, the shock interactions become stronger, resulting in much higher surface pressures near the flaps and on the 2 fins containing the flaps.

The resultant delta control forces and moments are shown in Table 7. These results seem to indicate that control force and moment are generated across the Mach number range considered. Also, the higher the Mach number, the larger the delta control forces and the moment for supersonic speeds,
$M>1.5$. It is interesting that control force and moment are generated at subsonic speed, $M=0.8$, as well as across the transonic speed regime, $0.9<M<1$. , and they are almost constant in this speed regime. It is clear that potential exists for these microflaps to provide some control authority at all speeds including subsonic and transonic. Computed results for this optimized 8-flap configuration are compared with the 4-flap baseline configuration (Figures 12 and 13). With only a slight penalty in drag, substantially larger control force and moment are obtained for the 8-flap configuration. 
TABLE 6: Variation of delta forces and moments due to microflaps with angle of attack, $M=2.5$.

\begin{tabular}{lccc}
\hline $\begin{array}{l}\text { Angle of } \\
\text { attack } \alpha\left(^{\circ}\right) .\end{array}$ & $\begin{array}{c}\text { Delta normal } \\
\text { force } \delta F_{z}(\mathrm{~N})\end{array}$ & $\begin{array}{c}\text { Delta pitching } \\
\text { moment } \delta M_{y}(\mathrm{~N}-\mathrm{m})\end{array}$ & $\begin{array}{c}\text { Delta axial } \\
\text { force }(\mathrm{N})\end{array}$ \\
\hline-16 & -100.0 & 13.19 & 49.1 \\
-12 & -91.7 & 11.96 & 43.9 \\
-8 & -91.7 & 11.91 & 39.7 \\
-4 & -81.6 & 10.49 & 33.7 \\
-2 & -72.0 & 9.19 & 28.7 \\
0 & -61.6 & 7.74 & 23.4 \\
2 & -52.5 & 6.48 & 19.2 \\
4 & -45.7 & 5.56 & 16.7 \\
8 & -44.5 & 5.29 & 16.0 \\
12 & -57.4 & 6.85 & 18.3 \\
16 & -64.0 & 7.51 & 19.2 \\
\hline
\end{tabular}

TABLE 7: Variation of delta forces and moments due to microflaps with Mach, $\alpha=0^{\circ}$.

\begin{tabular}{lccc}
\hline $\begin{array}{l}\text { Mach } \\
\text { number }\end{array}$ & $\begin{array}{c}\text { Delta normal } \\
\text { force } \delta F_{z}(\mathrm{~N})\end{array}$ & $\begin{array}{c}\text { Delta pitching } \\
\text { moment } \delta M_{y}(\mathrm{~N}-\mathrm{m})\end{array}$ & $\begin{array}{c}\text { Delta axial } \\
\text { force }(\mathrm{N})\end{array}$ \\
\hline 0.80 & -10.9 & 1.23 & 3.7 \\
0.90 & -12.8 & 1.44 & 5.1 \\
0.92 & -12.8 & 1.44 & 5.4 \\
0.95 & -12.6 & 1.40 & 5.8 \\
0.98 & -11.8 & 1.30 & 6.3 \\
1.1 & -13.7 & 1.51 & 7.7 \\
1.5 & -34.4 & 4.13 & 13.1 \\
2.0 & -47.8 & 5.92 & 18.5 \\
2.5 & -60.6 & 7.56 & 23.7 \\
3.0 & -73.7 & 9.25 & 29.0 \\
4.0 & -103.9 & 13.05 & 43.1 \\
5.0 & -135.2 & 17.00 & 59.2 \\
\hline
\end{tabular}

Also, note that microflaps are not effective with the baseline configuration at $M=1.2$ or less, whereas the new 8-flap configuration is still effective at $M=1.1$ and below at subsonic and transonic speeds.

These changes in the aerodynamic force and moments due to presence of microflaps can be used in 6DOF flight dynamic simulations to examine the feasibility of microflaps as control mechanism to provide adequate control authority for projectile control. For practical applications, the microflaps will need to go in and out as the body rolls depending on the desired control maneuver. For example, if a cross-range (or lateral) maneuver is needed, the microflaps can be actuated in the lateral $y$-direction for part of the roll cycle (and off for the remainder of the roll cycle) so control forces are generated in that direction and are used for lateral control of the projectile.

4.5. Flow Control Effect with Fins Removed. Here the effect of Mach number is studied using the same optimized 8-flap
TABLE 8: Delta forces and moments due to microflaps, no fins, $\alpha=$ $0^{\circ}$.

\begin{tabular}{lccc}
\hline $\begin{array}{l}\text { Mach } \\
\text { number }\end{array}$ & $\begin{array}{c}\text { Delta normal } \\
\text { force } \delta F_{z}(\mathrm{~N})\end{array}$ & $\begin{array}{c}\text { Delta pitching } \\
\text { moment } \delta M_{y}(\mathrm{~N}-\mathrm{m})\end{array}$ & $\begin{array}{c}\text { Delta axial } \\
\text { force }(\mathrm{N})\end{array}$ \\
\hline 0.80 & -2.19 & 0.23 & 1.5 \\
0.90 & -2.74 & 0.30 & 2.4 \\
0.92 & -2.90 & 0.31 & 2.6 \\
0.95 & -2.94 & 0.32 & 3.0 \\
0.98 & -2.74 & 0.30 & 3.6 \\
1.1 & -2.89 & 0.33 & 4.7 \\
1.5 & -9.11 & 1.14 & 8.5 \\
2.0 & -16.53 & 2.12 & 14.1 \\
2.5 & -24.32 & 3.13 & 19.9 \\
3.0 & -32.53 & 4.20 & 23.7 \\
4.0 & -50.92 & 6.56 & 37.9 \\
5.0 & -71.27 & 9.18 & 52.8 \\
\hline
\end{tabular}

configuration (case 4). This time, fins have been removed from the body. Of interest is the control force that would be generated on the body by the flaps with no fins. Again, computed results have been obtained for the optimized 8flap configuration at various speeds from $M=0.8$ to 5.0. Computed results (delta forces and delta pitching moment) are shown in Table 8 . For $0^{\circ}$ angle of attack, delta normal force is the same as the actual normal force, and the same is true for the delta pitching moment. The delta axial force is the difference between the axial forces with flaps and without flaps (body only). These results clearly show that control force and moment generated by the flaps are diminished nearly $50 \%$ at supersonic speeds and a little more at lower speeds when fins are removed. Also, the flaps are found to be ineffective at subsonic and transonic Mach numbers, Mach < 1.2 for the no-fin case. Although not shown here, results for the 8-flap no-fin case are similar to the 4-flap baseline case. That is pretty encouraging, but the fins do act as enablers for strong flow interactions leading to larger control authority and are needed as such.

\section{Conclusions}

This article describes a computational study undertaken to determine the free-flight aerodynamics of a finned projectile with flow control. The microflaps located between the rear fins of the projectile serve as the control mechanism for flow control. Advanced Navier-Stokes CFD techniques were used to compute the aerodynamics and the interaction effects associated with the microflap control mechanism.

Steady-state Navier-Stokes solutions were first obtained for the finned projectile both without and with microflaps at a supersonic velocity, $M=2.5$. Computed results for the configurations with the microflaps were first obtained at $0^{\circ}$ angle of attack. Different geometric parameters (i.e., flap locations, distance between the flaps, and the number of flaps) were varied to maximize the control authority. Control forces and moments were generated at this supersonic speed due 


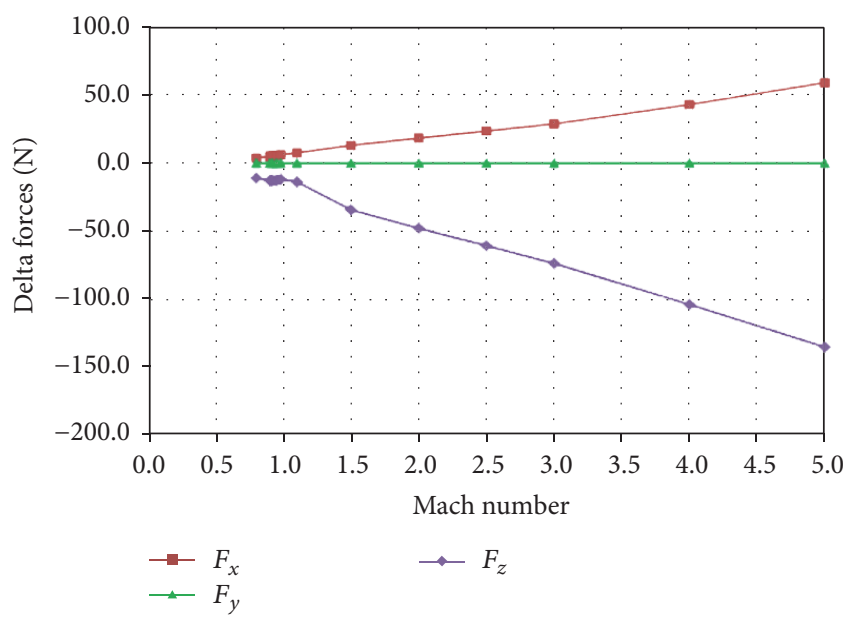

(a)

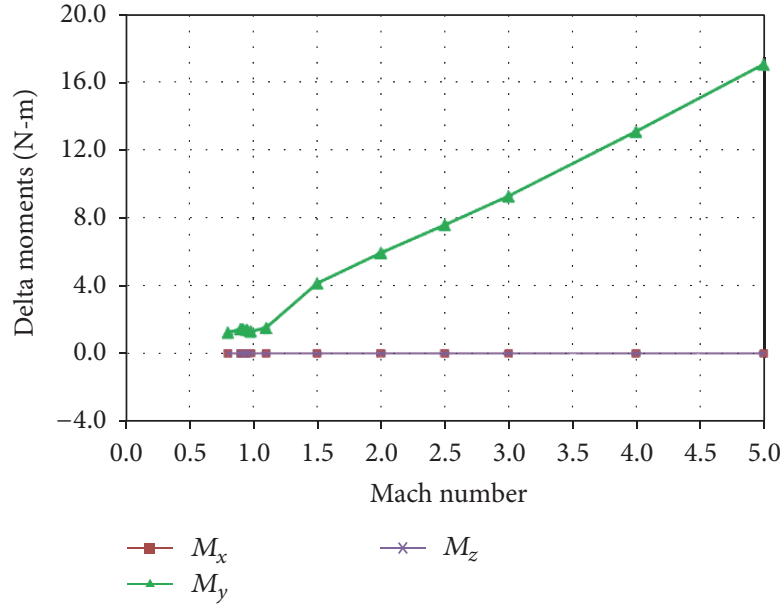

(b)

FIGURE 12: Variation of delta aerodynamic forces and moments due to microflaps as a function of Mach number for the 8-flap optimized configuration, $\alpha=0^{\circ}$ : (a) delta forces and (b) delta moments.

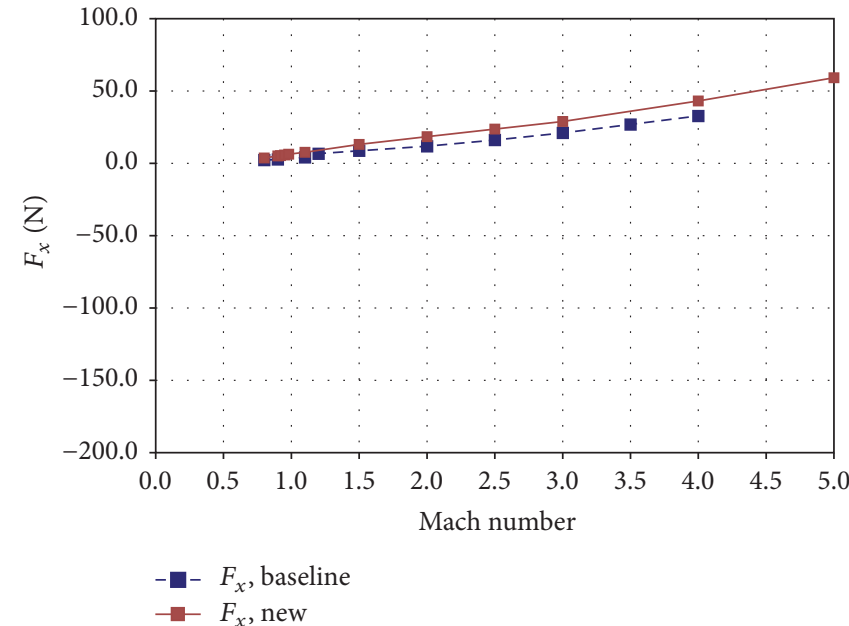

(a)

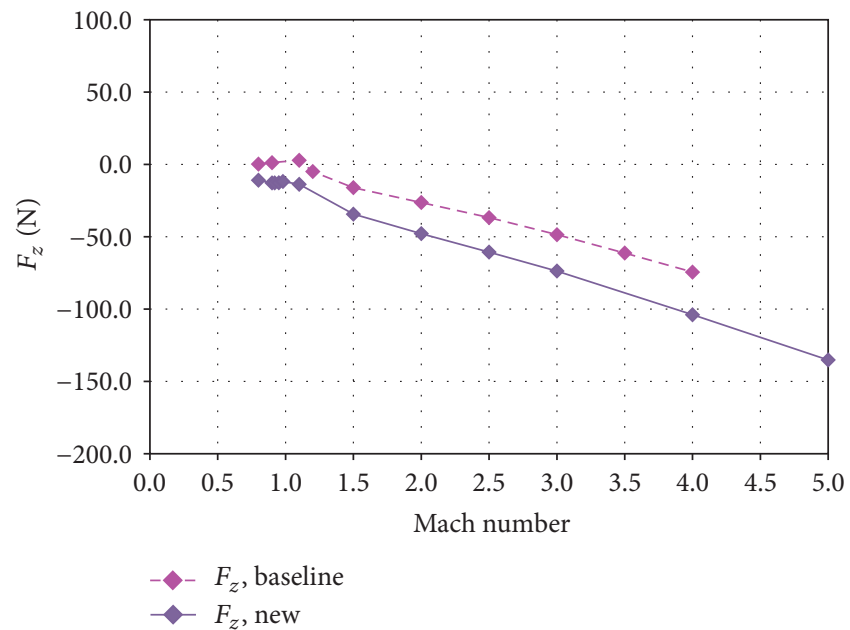

(b)

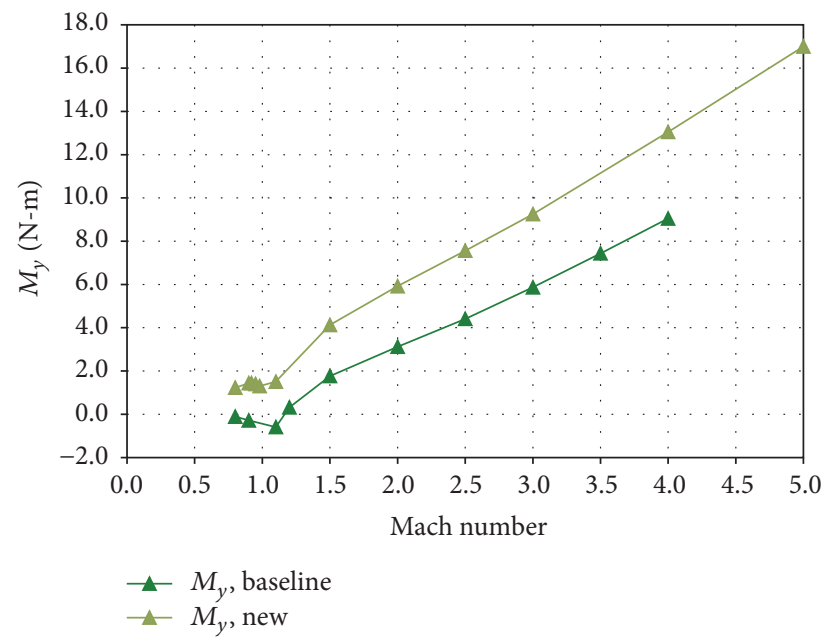

(c)

Figure 13: Comparison of delta forces and moment between the baseline and the optimized 8-flap configurations, $\alpha=0^{\circ}$ : (a) delta axial force, (b) delta normal force, and (c) delta pitching moment. 
to fin body-microflaps shock interactions resulting in higher pressures in the fin/body region containing the microflaps. Computed results obtained with the new 6- and 8-flap configurations produced larger control normal forces up to $21 \mathrm{~N}$ more than that produced by the baseline 4-flap configuration. Similar results were also obtained for the control pitching moment due to the microflaps. Computations were performed at this Mach for a range of angles of attack and control forces, and moments were also generated across the range of angle of attack considered.

An optimized 8-flap configuration was then selected and investigated for a range of Mach numbers from $M=0.8$ to 5 . These results show larger control forces and moments with increasing Mach number indicating that microflaps would be effective across these speeds with the new 8-flap configuration. This new configuration also produced substantially larger control force and moment than the baseline 4-flap configuration. The results also show that some control effectiveness of the microflaps exists even at transonic and subsonic speeds where the baseline 4-flap configuration failed. The substantially larger control force and moment generated by the microflaps with the new optimized 8-flap configuration, when used in a 6DOF flight dynamic analysis for crossrange control of the finned projectile, will clearly result in more control authority than the baseline 4-flap configuration.

This article has demonstrated the use of an advanced CFD technique to rapidly determine and maximize the control authority for a finned projectile with microflaps. More-sophisticated multidisciplinary design and optimization techniques can certainly be used, but it is presumed that the net gain by this intensive process may not be worth the extra time and effort. Additional research may be needed to include any unsteady effects that result from the actual deployment of microflaps. Time-accurate advanced CFD techniques can perhaps be used in the future to provide detailed understanding of the unsteady aerodynamics processes involving flow control mechanisms for advanced maneuvering munitions.

\section{Competing Interests}

The author declares that he has no competing interests.

\section{Acknowledgments}

The author would like to thank the US Department of Defense (DoD) High-Performance Computing Modernization program and the DoD Supercomputing Resource Centers for providing critically needed high-performance computer resources for the successful accomplishment of this work. The author also wishes to thank Metacomp Technologies personnel for their help with the mesh generation and the use of their unstructured meshing software and Jonathan Rogers, Georgia Institute of Technology, for providing partial funding of this work.

\section{References}

[1] F. G. Moore and L. Y. Moore, "Approximate method to calculate nonlinear rolling moment due to differential fin deflection," Journal of Spacecraft and Rockets, vol. 49, no. 2, pp. 250-260, 2012.

[2] Arrow Tech Associates, PRODAS User Manual, Arrow Tech Associates, South Burlington, Vt, USA, 1997.

[3] A. Dupuis and W. Hathaway, "Aeroballistic range tests of the basic finner reference projectile at supersonic velocities. Valcartier (Cananda): defence Research Establishment Valcartier," Tech. Rep. DREV-TM-9703, 1997.

[4] D. Orchard, E. Fournier, A. Dupuis, and J. Edwards, "Wind tunnel tests on the H3P78, power law, elliptic section flared projectile from mach 2.5 to 4," AIAA Paper 2001-4321, AIAA, Montreal, Canada, 2001.

[5] F. E. Fresconi, I. Celmins, M. Ilg, and J. Maley, "Projectile roll dynamics and control with a low-cost skid-to-turn maneuver system," Journal of Spacecraft and Rockets, vol. 51, no. 2, pp. 624627, 2014.

[6] A. Dupuis, "Aeroballistic range and wind tunnel tests of the basic finner reference projectile from subsonic to high supersonic velocities. Valcartier (Cananda): defence Research and Development Canada Valcartier," Tech. Rep. TM-2002-136, 2002.

[7] F. E. Fresconi, B. Guidos, I. Celmins, and W. Hathaway, "Flight behavior of an asymmetric body through spark range experiments using roll-yaw resonance for yaw enhancement," Tech. Rep. ARL-TR-7334, 2015.

[8] F. Fresconi and T. Harkins, "Experimental flight characterization of asymmetric and maneuvering projectiles from elevated gun firings," Journal of Spacecraft and Rockets, vol. 49, no. 6, pp. 1120-1130, 2012.

[9] J. Sahu, "Time-accurate computations of free-flight aerodynamics of a spinning projectile with and without flow control,' ' Report ARL-TR-3919, Army Research Laboratory (US), Aberdeen Proving Ground, Md, USA, 2006.

[10] S. I. Silton, "Navier-Stokes computations for a spinning projectile from subsonic to supersonic speeds," Journal of Spacecraft and Rockets, vol. 42, no. 2, pp. 223-231, 2005.

[11] J. DeSpirito, "Lateral jet interaction on a finned projectile in supersonic flow," in Proceedings of the AIAA 50th Aerospace Sciences Meeting, Nashville, Tenne, USA, January 2012.

[12] L. E. Ericsson and J. P. Reding, "Steady and unsteady vortexinduced asymmetric loads on slender vehicles," Journal of Spacecraft and Rockets, vol. 18, no. 2, pp. 97-109, 1981.

[13] T. Birch, I. E. Wrisdale, and S. Prince, "CFD predictions of missile flowfields," in Proceedings of the 18th Applied Aerodynamics Meeting, AIAA Paper No. 2000-4211, Denver, Colo, USA, August 2000.

[14] J. Sivasubramanian, R. D. Sandberg, D. A. Von Terzi, and H. F. Fasel, "Numerical investigation of transitional supersonic base flows with flow control," AIAA Journal of Spacecraft and Rockets, vol. 44, no. 5, pp. 1021-1028, 2007.

[15] T.-Y. Hsu, M. Hammache, and F. Browand, "Base flaps and oscillatory perturbations to decrease base drag," in The Aerodynamics of Heavy Vehicles: Trucks, Buses, and Trains, vol. 19 of Lecture Notes in Applied and Computational Mechanics, pp. 303-316, Springer, Berlin, Germany, 2004.

[16] M. P. Patel, C. P. Tilmann, and T. T. Ng, "Closed-loop missile yaw control via manipulation of forebody flow asymmetries," 
Journal of Spacecraft and Rockets, vol. 41, no. 3, pp. 436-443, 2004.

[17] C. Porter, C. Fagley, J. Farnsworth, J. Seidel, and T. McLaughlin, "Closed loop flow control of a tangent ogive at a high angle of attack," in Proceedings of the 51st AIAA Aerospace Sciences Meeting including the New Horizons Forum and Aerospace Exposition, 2013.

[18] V. Sirangu and T. Terry Ng, "Flow control of a slender bluntnose body at high angles of attack," Journal of Aircraft, vol. 49, no. 6, pp. 1904-1912, 2012.

[19] A. Gross and H. F. Fasel, "CFD for investigating active flow control (invited)," in Proceedings of the 4th AIAA Flow Control Conference, June 2008.

[20] L. N. Cattafesta III and M. Sheplak, "Actuators for active flow control," Annual Review of Fluid Mechanics, vol. 43, pp. 247-272, 2011.

[21] R. Woszidlo and I. Wygnanski, Parameters Governing Separation Control with Sweeping Jet Actuators, AIAA Paper 2011-3172, 2011.

[22] S. Gokoglu, M. Kuczmarski, D. Culley, and S. Raghu, "Numerical studies of a fluidic diverter for flow control," AIAA Paper 2009-4012, 2009.

[23] M. Zeidler, E. Garnier, R. Cayzac, and A. Merlen, "Fluidic control of a 155 millimeter spin-stabilized projectile using Coanda effect," AIAA Journal, vol. 53, no. 5, pp. 1146-1158, 2015.

[24] J. McMichael, A. Lovas, P. Plostins, J. Sahu, G. Brown, and A. Glezer, "Microadaptive flow control applied to a spinning projectile," Tech. Rep. ARL-TR-3589, 2005.

[25] M. Samimy, I. Adamovich, B. Webb et al., "Development and characterization of plasma actuators for high-speed jet control," Experiments in Fluids, vol. 37, no. 4, pp. 577-588, 2004.

[26] T. Corke and M. Post, "Overview of plasma flow control: concepts, optimization, and applications," in Proceedings of the 43rd AIAA Aerospace Sciences Meeting and Exhibit, AIAA 2005563, Reno, Nev, USA, January 2005.

[27] J. C. Lin, "Review of research on low-profile vortex generators to control boundary-layer separation," Progress in Aerospace Sciences, vol. 38, no. 4-5, pp. 389-420, 2002.

[28] J. Lopera, T. Ng, M. Patel, and S. Vasudevan, "Coning motion control of a blunt-nose projectile using small deployable strakes," in Proceedings of the 25th AIAA Applied Aerodynamics Conference, AIAA 2007-3812, Miami, Fla, USA, 2007.

[29] T. Terry Ng, "Effect of a single strake on the forebody vortex asymmetry," Journal of Aircraft, vol. 27, no. 9, pp. 844-846, 1990.

[30] K. Kontis, "Flow control effectiveness of jets, strakes, and flares at hypersonic speeds," Proceedings of the Institution of Mechanical Engineers Part G: Journal of Aerospace Engineering, vol. 222, no. 5, pp. 585-603, 2008.

[31] E. J. Stephen, S. P. Morell, R. Decker, D. K. Hope, and T. E. McLaughlin, "Flow interactions of small cylindrical protuberances and the supersonic turbulent boundary layer on a flat plate," in Proceedings of the 52nd Aerospace Sciences Meeting, National Harbor, Md, USA, January 2014.

[32] K. Garon, G. Abate, and W. Hathaway, "Free-flight testing of generic missile with MEMs protuberances," in Proceedings of the 41st Aerospace Sciences Meeting and Exhibit, AIAA 2003-1242, Reno, Nev, USA, January 2003.

[33] E. L. Blades and D. L. Marcum, "Numerical simulation of a spinning missile with dithering canards using unstructured grids," Journal of Spacecraft and Rockets, vol. 41, no. 2, pp. 248-256, 2004.
[34] M. Landers, L. Hall, L. Auman, and M. Vaughn, "Deflectable nose and canard controls for a fin-stabilized projectile at supersonic and hypersonic speeds," in Proceedings of the 21st AIAA Applied Aerodynamics Conference, AIAA, Orlando, Fla, USA, 2003.

[35] J. Brandeis and J. Gill, "Experimental investigation of sidejet steering for supersonic and hypersonic missiles," Journal of Spacecraft and Rockets, vol. 33, no. 3, pp. 346-352, 1996.

[36] J. Brandeis and J. Gill, "Experimental investigation of super- and hypersonic jet interaction on missile configurations," Journal of Spacecraft and Rockets, vol. 35, no. 3, pp. 296-302, 1998.

[37] M. J. Graham and P. Weinacht, "Numerical investigation of supersonic jet interaction for axisymmetric bodies," Journal of Spacecraft and Rockets, vol. 37, no. 5, pp. 675-683, 2000.

[38] M. J. Graham, P. Weinacht, and J. Brandeis, "Numerical investigation of supersonic jet interaction for finned bodies," Journal of Spacecraft and Rockets, vol. 39, no. 3, pp. 376-383, 2002.

[39] J. DeSpirito, "Transient lateral jet interaction effects on a generic fin-stabilized projectile," in Proceedings of the 30th AIAA Applied Aerodynamics Conference, pp. 1060-1078, New Orleans, La, USA, June 2012.

[40] B. Zhang, S. Wang, M. Cao, and Y. Xu, "Impacts of deflection nose on ballistic trajectory control law," Mathematical Problems in Engineering, vol. 2014, Article ID 984840, 6 pages, 2014.

[41] B. Shoesmith, T. Birch, M. Mifsud, M. Meunier, and S. Shaw, "CFD analysis of a supersonic projectile with deflectable nose control," in Proceedings of the 3rd AIAA Flow Control Conference, Fluid Dynamics and Co-Located Conferences, AIAA 20063200, San Francisco, Calif, USA, 2006.

[42] D. Corriveau, N. Hamel, and F. C. Wong, "Force and moment measurements on a generic finned missile with nose-mounted micro-structures," in Proceedings of the 45th AIAA Aerospace Sciences Meeting, pp. 3399-3409, Reno, Nev, USA, January 2007.

[43] M. Patel, J. DiCocco, T. Prince, and T. Ng, "Afterbody flow control for low- $\alpha$ missile maneuvering," in Proceedings of the 21st AIAA Applied Aerodynamics Conference, AIAA 2003-3673, Orlando, Fla, USA, 2003.

[44] L. A. Johnson and P. Sprangle, "Guiding supersonic projectiles using optically generated air density channels," Journal of Applied Physics, vol. 118, no. 12, Article ID 123301, 2015.

[45] N. J. Bisek, I. D. Boyd, and J. Poggie, "Numerical study of electromagnetic aerodynamic control of hypersonic vehicles," in Proceedings of the 47th AIAA Aerospace Sciences Meeting including the New Horizons Forum and Aerospace Exposition, January 2009.

[46] J. Sahu and K. R. Heavey, "Parallel CFD computations of projectile aerodynamics with a flow control mechanism," Computers and Fluids, vol. 88, pp. 678-687, 2013.

[47] P. Gnemmi, R. Charon, J.-P. Dupéroux, and A. George, "Feasibility study for steering a supersonic projectile by a plasma actuator," AIAA Journal, vol. 46, no. 6, pp. 1308-1317, 2008.

[48] P. Gnemmi and C. Rey, "Plasma actuation for the control of a supersonic projectile," Journal of Spacecraft and Rockets, vol. 46, no. 5, pp. 989-998, 2009.

[49] K. C. Massey, K. B. Guthrie, and S. I. Silton, "Optimized guidance of a supersonic projectile using pin based actuators," in Proceedings of the 23rd AIAA Applied Aerodynamics Conference, pp. 778-790, Toronto, Canada, June 2005.

[50] K. C. Massey and S. I. Silton, "Testing the maneuvering performance of a mach 4 projectile," in Proceedings of the 24th AIAA Applied Aerodynamics Conference, June 2006. 
[51] D. L. Cler, R. Carson, R. Dillon, and M. Costello, "Flow manipulation of a fin on a flat plate interaction in high-speed flow by means of micro flaps," Final Report ADA588653, U.S. Army Armament Research Development and Engineering Center, Benét Laboratories, Watervliet, NY, USA, 2009.

[52] J. Dykes, M. Costello, D. L. Cler, R. Carson, and R. Dillon, "Use of micro spoilers for control of finned projectiles," in Proceedings of the AIAA Atmospheric Flight Mechanics Conference, Toronto, Canada, August 2010.

[53] E. Scheuermann, M. Costello, S. Silton, and J. Sahu, "Aerodynamic characterization of a microspoiler system for supersonic finned projectiles," Journal of Spacecraft and Rockets, vol. 52, no. 1, pp. 253-263, 2015.

[54] B. L. Smith and A. Glezer, "The formation and evolution of synthetic jets," Physics of Fluids, vol. 10, no. 9, pp. 2281-2297, 1998.

[55] M. Amitay, V. Kibens, D. Parekh, and A. Glezer, "The dynamics of flow reattachment over a thick airfoil controlled by synthetic jet actuators," in Proceedings of the 37th Aerospace Sciences Meeting and Exhibit, Aerospace Sciences Meetings, AIAA Paper No. 99-1001, Reno, Nev, USA, 1999.

[56] Y. He and L. Kral, "Post-stall control on an airfoil using localized jet actuators," AIAA Paper no. 2000-0408, 2000.

[57] J. Sahu, "CFD simulations of a finned projectile with microflaps for flow control," in Proceedings of the 27th International Conference on Parallel CFD, Montreal, Canada, May 2015.

[58] O. Peroomian and S. Chakravarthy, "A grid-transparent methodology for CFD," in Proceedings of the 35th Aerospace Sciences Meeting, AIAA Paper 97-0724, Reno, Nev, USA, 1997.

[59] P. Batten, U. Goldberg, and S. Chakravarthy, "Sub-grid turbulence modeling for unsteady flow with acoustic resonance," in Proceedings of the 38th Aerospace Sciences Meeting and Exhibit, Reno, Nev, USA, January 2000.

[60] O. Peroomian, S. Chakravarthy, S. Palaniswamy, and U. Goldberg, "Convergence acceleration for unified-grid formulation using preconditioned implicit relaxation," AIAA Paper no. 980116, 1998.

[61] U. Goldberg, O. Peroomian, and S. Chakravarthy, "A wall-distance-free $\mathrm{k}-\varepsilon$ model with enhanced near-wall treatment," Journal of Fluids Engineering, Transactions of the ASME, vol. 120, no. 3, pp. 457-462, 1998. 


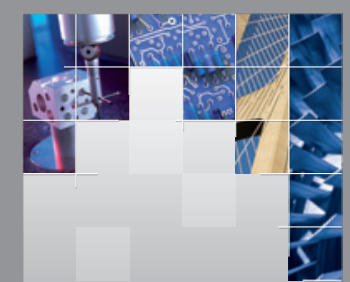

\section{Enfincering}
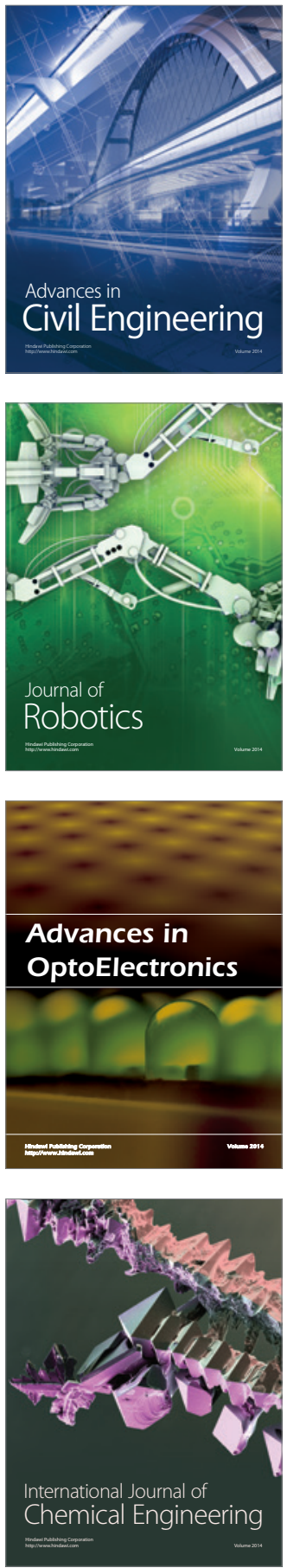

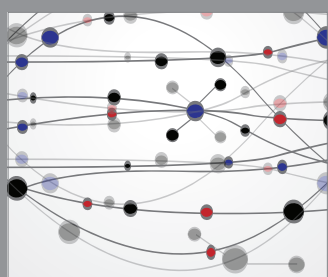

The Scientific World Journal

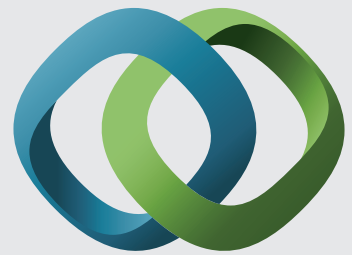

\section{Hindawi}

Submit your manuscripts at

https://www.hindawi.com
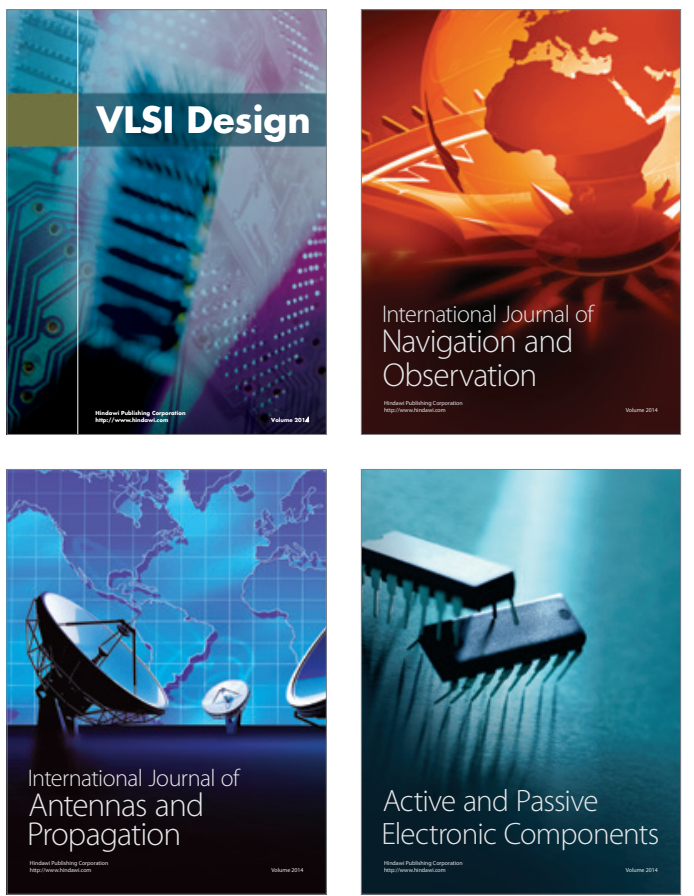
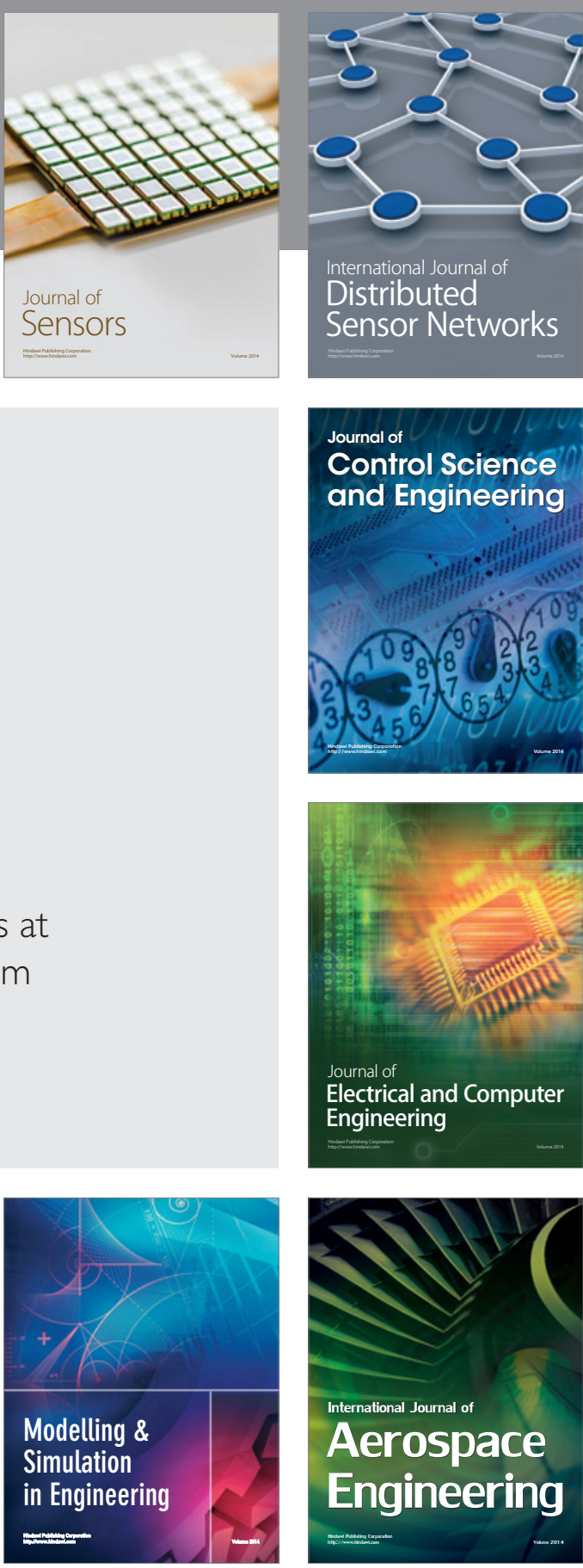

International Journal of

Distributed

Sensor Networks

$-$

Joumal of

Control Science

and Engineering
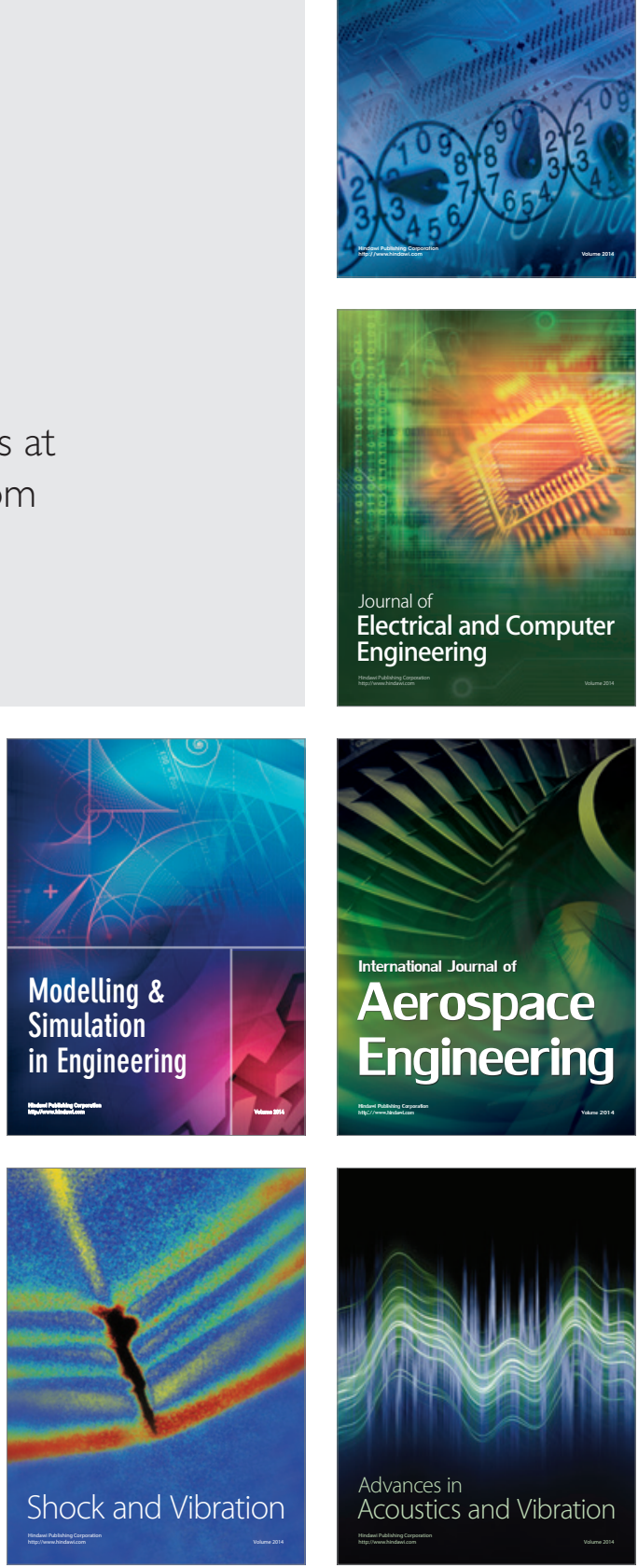